\title{
Commentary: Frozen elephant trunk in type A aortic dissection-Is it time to play the long game?
}

\author{
Clifford W. Barlow, FRCS (CTh), DPhil (Oxon), ${ }^{a}$ and Abe DeAnda, Jr, MD ${ }^{\mathrm{b}}$
}

\footnotetext{
From the ${ }^{\mathrm{a} D e p}$ artment of Cardiothoracic Surgery, University Hospital Southampton, Southampton, United Kingdom; and the ${ }^{\mathrm{b}}$ Division of Cardiovascular and Thoracic Surgery, UTMB-Galveston, Galveston, Tex. Disclosures: Authors have nothing to disclose with regard to commercial support.

Received for publication March 28, 2019; accepted for publication March 28, 2019; available ahead of print May $14,2019$.

Address for reprints: Abe DeAnda, Jr, MD, Division of Cardiothoracic Surgery, UTMB-Galveston, 301 University Blvd, Galveston, TX 77551 (E-mail: abdeanda@utmb.edu).

J Thorac Cardiovasc Surg 2020;159:1197-8

$0022-5223 / \$ 36.00$

Copyright (c) 2019 by The American Association for Thoracic Surgery

https://doi.org/10.1016/j.jtcvs.2019.03.113
}

The accepted short-term strategy for treating acute type A aortic dissection (ATAAD) remains unchanged-to save the patient's life by excluding the tear, replacing the ascending aorta, preserving aortic valve competence and coronary flow, preventing distal malperfusion, and avoiding neurologic injury. In the long-term, almost two-thirds of patients treated for ATAAD may have false-lumen persistency, some which may require surgical reintervention on the distal aorta. ${ }^{1,2}$

In this edition of the Journal, Poon and colleagues ${ }^{3}$ have analyzed the ARCH registry database to assess the safety of total arch replacement (TAR) with frozen elephant trunk (FET) in the setting of ATAAD. Of the 11,928 patients from the 37 centers contributing to the registry, they identify 978 who underwent TAR for ATAAD, 471 of whom also underwent FET. In reporting outcomes, predominantly inhospital mortality and neurologic and spinal cord complications, they analyze the whole group as well as 149 propensity-matched pairs. They describe an overall mortality for the group of $14.4 \%$, with no difference in permanent neurological deficit with TAR including FET (10.1\% vs $11.9 \%$ ). In the overall sample, spinal cord injury appeared to be higher in the patients undergoing TAR with FET $(3.9 \%$ vs $1.5 \% ; P<.05)$, but this difference was apparently not significant after propensity matching (6.3\% vs $4.0 \%$; difference not significant). Poon and colleagues ${ }^{3}$ acknowledge important limitations of their study, including the heterogeneous centers in 3 continents, and differing operative and FET deployment techniques, and various methods of neurological protection. They conclude that the use of FET for ATAAD does not appear to increase the risk of paraplegia in appropriately selected patients at experienced centers.

In interpreting the study of Poon and colleagues, ${ }^{3}$ the reader should differentiate between the early findings they report from the very large ARCH database and their potential long-term clinical significance. The main finding was that ATAAD repair including TAR replacement had nal cord injury.

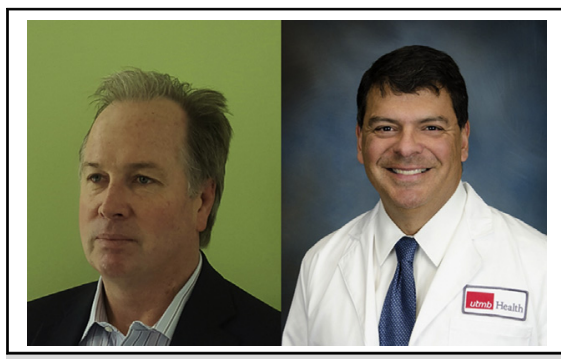

Clifford W. Barlow, FRCS (CTh), DPhil (Oxon) (left), and Abe DeAnda, Jr, MD (right).

Central Message

The routine use of the frozen elephant trunk technique in the setting of an acute type A dissection may not have a demonstrable downside, including neurologic complications.

See Article page 1189 .

similar mortality and neurologic and spinal injury rates regardless of whether FET was also inserted. There are too many limitations and confounding variables in the study to be certain whether these findings would stand up in a prospective evaluation, with consistent strategies, or shorter, more advanced FET devices. Statistical comparisons of the propensity pairs must also be regarded with caution, because the groups were unmatched in many respects. The real message that the study conveys, however, is both interesting and provocative. It appears that in established centers, with advanced techniques, ATAAD repair including TAR with FET insertion can be achieved with comparable mortality and neurological injury rates to those reported by others with more conservative strategies. Spinal cord injury rates reported ${ }^{3}$ are also relatively low, whether $2.7 \%$ for the whole group or $3.9 \%$ for those with TAR and FET. These rates will always be higher than the negligible spinal cord injury rates observed in conservative ATAAD repair with replacement of the ascending aorta alone when there is no preoperative distal malperfusion. Nevertheless, patients with ATAAD who undergo both TAR and FET could have significant longterm survival advantages as a result of false-lumen thrombosis and because of the availability of a proximal landing site for future endovascular intervention, and these advantages could well offset the relatively small early risk of spi- 
The sporting expression "playing the long game" implies devising a strategy to have good short-term outcomes but also having a long-term plan and goals. Surgeons could replace a degenerative mitral valve or use vein grafts in coronary surgery with excellent in-hospital survival. This course is not defensible, however, in the era of mitral valve repair or when arterial graft strategies provide better long-term outcomes. Poon and colleagues ${ }^{3}$ report short-term outcomes in ATAAD equivalent to those seen when more conservative strategies are used, but with additional advantages of TAR and FET insertion. These could provide significantly improved long-term outcomes. Is it time to play the long game in this lethal condition too?

\section{References}

1. Kimura N, Itoh S, Yuri K, Adachi K, Matsumoto H, Yamaguchi A, et al. Reoperation for enlargement of the distal aorta after initial surgery for acute type A aortic dissection. J Thorac Cardiovasc Surg. 2015;149(2 Suppl):91-8.e1.

2. Halstead JC, Meier M, Etz C, Spielvogel D, Bodian C, Wurm M, et al. The fate of the distal aorta after repair of acute type A aortic dissection. J Thorac Cardiovasc Surg. 2007; 133:127-35

3. Poon SS, Tian DH, Yan T, Harrington D, Nawaytou O, Kuduvalli M, et al; on behalf of the International Aortic Arch Surgery Study Group. Frozen elephant trunk does not increase incidence of paraplegia in patients with acute type A aortic dissection. J Thorac Cardiovasc Surg. 2020;159:1189-96.e1. 